\title{
POLA KERAPATAN DAN KERAGAMAN TEGAKAN HUTAN DIPTEROKARPA SEKUNDER \\ (Pattern of Density and Diversity of Secondary Dipterocarps Forest Stand)
}

\author{
Farida Herry Susanty* \\ Balai Besar Penelitian dan Pengembangan Ekosistem Hutan Dipterokarpa \\ Jl. A.Wahab Syahrani No.68, Sempaja, Samarinda; Tlp. (0541) 206364, Fax (0541) 742298 \\ *E-mail: fhsusanty@gmail.com \\ Tanggal diterima: 27 Februari 2020; Tanggal disetujui: 29 April 2020; Tanggal direvisi: 13 Mei 2020
}

\begin{abstract}
The assessment of dipterocarp secondary forest recovery has important parameters namely stand density and diversity of forest species composition. This study aims to determine trends in patterns of change in density and diversity of secondary dipterocarp stands in natural forests based on variations in logging aged as projections of natural recovery that occurs in production natural forests. The study was conducted at the Natural Forest IUPHHK of PT. Gunung Gajah Abadi, Wahau, East Kalimantan. Data collection period on 2016-2019 by building temporary sampling plots of 11 plots (11 hectares) on 7 variations of logging aged. Density parameters (i.e. number of trees and basal area per unit area) and diversity (number of species, heterogeneity index, species abundance and evenness index) of Dipterocarp secondary forest stands will vary over the logging aged. The form of the relationship of stand density, abundance index and species evenness index is logarithmic regression form, while for base field parameter, the number and index of species diversity are polynomial or quadratic regression. Aged stands after logging is a factor that influences quite a large number of species composition, but is not large enough for other stand density and diversity parameters.
\end{abstract}

Keywords: Basal area, index heterogeneity, species abundance, evenness index, density

\begin{abstract}
ABSTRAK
Penilaian pemulihan hutan sekunder dipterokarpa mempunyai parameter penting, yaitu kerapatan tegakan dan keragaman komposisi jenis hutan. Penelitian ini bertujuan untuk mengetahui kecenderungan pola perubahan kerapatan dan keragaman tegakan pada hutan alam dipterokarpa sekunder berdasarkan variasi umur tebangan sebagai proyeksi tingkat pemulihan (recovery) alami yang terjadi pada hutan alam produksi. Penelitian dilaksanakan di IUPHHK Hutan Alam PT Gunung Gajah Abadi, Wahau, Kalimantan Timur. Periode pengumpulan data pada tahun 2016-2019 dengan pembuatan plot sampling temporer sebanyak 11 plot (seluas 11 ha) pada tujuh variasi umur tebangan. Parameter kerapatan (jumlah pohon dan bidang dasar per satuan luas) dan keragaman (jumlah jenis, indeks keanekaragaman, kelimpahan jenis dan indeks kemerataan jenis) tegakan hutan sekunder dipterokarpa akan bervariasi sepanjang umur tebangan. Bentuk hubungan parameter kerapatan tegakan, indeks kelimpahan dan indeks kemerataan jenis adalah berbentuk regresi logaritma, sedangkan untuk parameter bidang dasar tegakan, jumlah dan indeks keanekaragaman jenis berbentuk regresi polynomial atau kuadratik. Umur tegakan setelah penebangan merupakan faktor yang memengaruhi cukup besar terhadap komposisi jumlah jenis, tetapi tidak cukup besar untuk parameter kerapatan dan keragaman tegakan lainnya.
\end{abstract}

Kata kunci: Bidang dasar, indeks keanekaragaman, kelimpahan jenis, indeks kemerataan, kerapatan 


\section{PENDAHULUAN}

Hutan dipterokarpa campuran sebagai bagian dari hutan hujan daratan rendah dengan tingkat produktivitas dan keanekaragaman yang tinggi. Sebagian besar hutan dipterokarpa merupakan hutan alam produksi yang secara kontinyu dilakukan penebangan. Berdasarkan data dalam Rekalkulasi Penutupan Lahan Indonesia Tahun 2014-2018, Kementerian Lingkungan Hidup dan Kehutanan (KLHK) pada tahun 2019, luas hutan alam produksi baik dengan status tetap maupun terbatas mencapai 38,76 juta ha atau mencakup 48,33\% dari luas areal berhutan, sedangkan hingga tahun 2018, dari total luasan areal hutan tersebut, kondisi hutan sekunder mencapai $45,18 \%$ (Direktorat IPSDH, 2019). Kondisi ini semakin meningkat sejalan dengan kegiatan penebangan yang terus berlangsung. Jika kondisi tersebut terus berlangsung diprediksi pada tahun 2020 luas hutan yang tersisa hanya sepertiga bagian dari luas hutan tetap (Sifriyani, Ruslan, \& Susanty, 2019).

Kondisi hutan yang terdegradasi mempunyai dampak ekologis yang sangat komplek mencakup gangguan terhadap struktur tegakan, komposisi jenis hingga biomassa tegakan (Portier, Gauthier, Cyr, \& Bergeron, 2018). Penebangan pohon akan terjadi perubahan kanopi yang membentuk gap atau ruang dalam tegakan. Dampak utama dari hal ini adalah perubahan struktur tegakan dan keragaman keanekaragaman hayati komposisi penyusun tegakan (Susanty, 2016). Dampak tidak langsung berupa ancaman terhadap turunnya kualitas lingkungan dengan perubahan seperti erosi tanah dan perubahan siklus hidrologi karena hutan merupakan suatu ekosistem. Tegakan setelah penebangan akan berubah dengan berkurangnya kerapatannya dan akan menurunkan tingkat biodiversitas atau keragamannya. Hutan secara alami mempunyai kemampuan untuk memulihkan kondisi setelah terdegradasi. Pada kondisi hutan alam yang mempunyai ragam kondisi, tingkat pemulihan ini juga akan bervariasi. Kondisi kerapatan dan tingkat keragaman tegakan merupakan salah satu indikator yang menunjukkan keseimbangan ekosistem setelah gangguan (Sreelekshmi et al., 2018).

Hutan sekunder mempunyai struktur yang sederhana dibandingkan dengan hutan primer (Susanty, 2019). Berkurangnya kerapatan dan bidang dasar tegakan akan menurunkan kurva struktur. Struktur tegakan merupakan bentuk ekofisiologis dari faktor tipe ekosistem sebagai respon dari tingkat gangguan terhadap tegakan hutan dan lingkungan sekaligus juga menunjukkan tingkat suksesi atau pemulihan hutan (Sapkota, Stahl, \& Norton, 2019; Pretzsch, 2020). Kerapatan merupakan indikator tegakan yang utama dalam menentukan tingkat hasil produksi yang akan diperoleh dalam hutan alam produksi pada siklus berikutnya hingga memengaruhi kualitas kayu yang dihasilkan (Newton, 2019; Pretzsch, 2020). Aspek keanekaragaman komposisi jenis pada hutan bekas tebangan mempunyai tingkat yang masih rendah hingga sedang dibandingkan dengan hutan primer (Susanty, 2016).

Penelitian bertujuan untuk mengetahui kecenderungan pola perubahan kerapatan dan keragaman tegakan pada hutan alam dipterokarpa sekunder berdasarkan variasi umur tebangan sebagai proyeksi tingkat pemulihan (recovery) alami yang terjadi pada hutan alam produksi. Penilaian ini mencakup parameter produktivitas dan konservasi keanekaragaman hayati dalam struktur tegakan hutan alam.

\section{METODOLOGI}

\section{A. Lokasi dan Waktu Penelitian}

Penelitian dilakukan di areal Unit Pengusahaan Hutan (UPH) PT Gunung Gajah Abadi (GGA) yang secara geografis areal kerja terletak pada $116^{\circ} 40^{\prime}-117^{\circ} 02^{\prime}$ Bujur Timur dan $1^{\circ} 20^{\prime}-1^{\circ} 35^{\prime}$ Lintang Utara. Areal kerja termasuk dalam 
Kelompok Hutan Sungai Seleq, Resort Pemangkuan Hutan (RPH) Sungai Seleq, Bagian Kesatuan Pemangkuan Hutan Muara Wahau, Cabang Dinas Kehutanan Mahakam Tengah. Secara administratif berada di Desa Miau Baru, Kecamatan Kong Beng Kabupaten Kutai Timur, Propinsi Kalimantan Timur. Penelitian dilakukan dari tahun 2016 sampai 2019.

\section{B. Metode}

\section{Tahapan pelaksanaan}

Pengumpulan data dilakukan dengan pembangunan plot sampling temporer pada tegakan hutan setelah penebangan secara purposive dengan variasi umur tebangan pada kelas umur tebangan muda, sedang dan tua. Pembangunan plot sampling sebanyak 1-2 plot pada satu kelas umur tebangan yang tergantung pada kondisi aksesibilitas.

Desain plot sampling yang dibangun pada masing-masing kondisi tegakan bekas tebangan dengan ukuran $100 \mathrm{~m} \mathrm{x}$ $100 \mathrm{~m}$ (1 ha) dengan ukuran sub plot adalah $20 \mathrm{~m} \times 20 \mathrm{~m}$ sebanyak 25 buah. Pengumpulan data tegakan pada tiap plot sampling meliputi pengukuran data tegakan tinggal dengan sistem inventarisasi secara sensus untuk semua jenis pohon yang mempunyai limit diameter $10 \mathrm{~cm}$ atau keliling $31,4 \mathrm{~cm}$ (setinggi dada $130 \mathrm{~cm}$ atau $20 \mathrm{~cm}$ di atas banir). Periode pengumpulan data melalui pembangunan plot sampling dan inventarisasi tegakan, yaitu pada tahun 2016-2019. Dalam penelitian ini digunakan data dari pembangunan 11 plot sampling (seluas $11 \mathrm{ha}$ ) yang berada di tujuh variasi umur tebangan, yaitu pada hutan sekunder 4, 8, 10, 13, 14, 15 dan 33 tahun setelah penebangan.

\section{Pengolahan dan analisis data}

Proses pengolahan dan analisis data menggunakan program spreadsheet dan SPSS Statistik 24. Perhitungan nilai parameter kerapatan dan keragaman tegakan menggunakan rumus umum sebagai berikut:

1) Kerapatan pohon per hektar $=\frac{\text { Jumlah pohon }}{\text { Luas plot }} \ldots$

2) $\mathrm{Bd}=\Sigma\left(1 / 4 \cdot \pi \cdot \mathrm{d}^{2}\right) /$ luas plot

Dimana: $\mathrm{Bd}=$ Bidang dasar pohon $\left(\mathrm{m}^{2} / \mathrm{ha}\right)$,

$\mathrm{d}=$ Diameter pohon $(\mathrm{cm})$,

$\pi=$ Konstanta $(3,1415)$.

3) Jumlah jenis berdasarkan hasil identifikasi botanis (J).

4) Indeks Keanekaragaman Jenis (Species Heterogenity Index) Shanon \& Wiener:

$$
\mathrm{H}^{\prime}=-\sum_{i=1}^{n}\left(\frac{n i}{N}\right) \log \left(\frac{n i}{N}\right)
$$

Dimana: $H^{\prime}=$ Indeks keanekaragaman jenis,

$\mathrm{n}_{\mathrm{i}}=$ Jumlah individu jenis ke-i,

$\mathrm{N}=$ Jumlah individu seluruh jenis.

5) Kelimpahan spesies:

$$
\mathrm{N}_{1}=\mathrm{e}^{\mathrm{H}}
$$

Dimana: $\mathrm{N}_{1}=$ Jumlah kelimpahan species,

$\mathrm{e}=2,71828$,

$\mathrm{H}^{\prime}=$ Indeks keanekaragaman jenis.

6) Indeks Kemerataan Jenis (Evenness) Pielou J':

$$
\mathrm{E}=\frac{H^{t}}{\operatorname{Ln}(S)}
$$

Dimana: $\mathrm{E}=$ Indeks kemerataan,

$\mathrm{H}^{\prime}=$ Indeks keanekaragaman,

$\mathrm{S}=$ Jumlah jenis.

Bentuk hubungan masing-masing parameter tegakkan berdasarkan umur tebangan ditunjukkan berdasarkan analisis regresi korelasi. Persamaan regresi yang dicobakan adalah persamaan linear, polynomial/kuadratik, eksponensial dan logaritma.

$$
\begin{array}{lr}
Y=\alpha+\beta X & (\text { Linear) } \ldots .(6) \\
Y=\alpha+\beta_{1} X+\beta_{2} X^{2} & (\text { Polinomial) } \ldots .(7) \\
Y=\alpha \mathrm{e}^{\beta X} & (\text { Eksponensial) } \ldots .(8) \\
Y=\alpha+\beta \log & (\text { Logaritma) } \ldots . .(9)
\end{array}
$$


Pemilihan model yang paling sesuai dilakukan dengan diagram scatter technique berdasarkan nilai koefisien korelasi (r) dan koefisien determinasi $\left(\mathrm{R}^{2}\right)$ tertinggi dan nilai kesalahan baku (SE) terkecil dengan menggunakan software SPSS statistik 24.

\section{HASIL DAN PEMBAHASAN}

\section{A. Hasil}

Sebelas plot sampling yang terbangun merupakan representasi variasi kondisi tegakan pada tujuh umur tebangan yang berbeda. Penilaian kerapatan tegakan berdasarkan nilai kerapatan jumlah batang tegakan dan nilai bidang dasar tegakan dalam satuan luas. Penilaian keragaman tegakan berdasarkan nilai parameter ekologis meliputi: jumlah jenis, indeks keanekaragaman, indeks kelimpahan dan indeks kemeratan jenis. Parameter kerapatan sebagai representasi aspek produktivitas, sedangkan parameter keragaman dari aspek konservasi ekologi jenis. Rekapitulasi perhitungan parameter kerapatan dan keragaman tegakan disajikan pada Tabel 1.

Kondisi aspek produktivitas menunjukkan nilai parameter kerapatan yang beragam. Baik kerapatan dalam jumlah pohon dan bidang dasar tegakan dalam satuan luas mempunyai variasi antar umur tebangan. Tidak terlihat kecenderungan (trend) yang jelas dengan kenaikan atau bertambahnya umur tebangan pada tegakan hutan sekunder terhadap parameter kerapatan tegakan. Rentang umur tegakan sekunder yaitu 4-33 tahun setelah penebangan, mempunyai simpangan baku nilai kerapatan 98 pohon/ha dan simpangan baku yang cukup kecil untuk nilai bidang dasar tegakan yaitu 4,26 $\mathrm{m}^{2} / \mathrm{ha}$. Hal ini dimungkinkan karena adanya variasi tingkat kerapatan tegakan awal saat sebelum penebangan. Adanya intensitas penebangan yang berbeda merupakan faktor yang membentuk tegakan tinggal akan mempunyai kondisi kerapatan dan struktur yang berbeda. Pada penelitian ini tidak diketahui data awal tegakan sebelum penebangan dan besarnya intensitas penebangan yang terjadi pada plot sampling yang dibangun.

Tingkat keragaman tegakan berdasarkan parameter jumlah jenis yang diobservasi, pada umur tebangan di bawah lima tahun menunjukkan jumlah yang lebih besar dibandingkan setelahnya. Pada kurun umur 8-33 tahun setelah penebangan mempunyai jumlah jenis yang mendekati serupa yaitu berkisar antara 2632 jenis. Jumlah jenis ini sangat dipengaruhi oleh kemampuan para botanis pendamping dalam mengidentifikasi jenis. Beberapa jenis hanya dapat diidentifikasi hingga tingkat genus bahkan hanya pada tingkat famili. Berdasarkan parameter indeks keanekaragaman, kelimpahan jenis dan indeks kemerataan mempunyai klasifikasi yang sama untuk semua umur tebangan. Pada rentang umur 4-33 tahun setelah penebangan, tegakan mempunyai kondisi keanekaragaman yang rendah (klasifikasi Magguran H' < 3), kelimpahan jenis yang rendah (klasifikasi Magguran $\mathrm{N}_{1}<1$ ) dan sebaran dominansi jenis kurang merata pada semua jenis yang ada (klasifikasi Magguran E'<0,5).

Hal ini menunjukkan bahwa tegakan hutan dipterokarpa sekunder sangat responsif terhadap perubahan keragaman jenis penyusun tegakan, tetapi lebih resisten atau mampu untuk memulihkan dirinya untuk aspek produktivitasnya. Tegakan sekunder setelah penebangan mempunyai kemampuan untuk memulihan secara alami.

Bentuk hubungan antara masingmasing parameter tegakan tersebut terhadap umur tebangan tegakan hutan didekati dengan analisis regresi dengan melihat korelasi kedua parameter tersebut. Empat bentuk regresi yang dicobakan adalah linear, eksponensial, kuadratik/ polinomial dan logaritma.

Berdasarkan nilai koefisien korelasi (r), koefisien determinasi $\left(\mathrm{R}^{2}\right)$, kesalahan baku (SE) dan analisis varians (F-hitung) 
(Tabel 2), maka rekapitulasi bentuk masing-masing parameter tegakan persamaan regresi yang terpilih untuk disajikan pada Tabel 3.

Tabel (Table) 1. Kerapatan dan keragaman tegakan pada variasi umur tebangan (Stand density and diversity on variation of logging aged)

\begin{tabular}{|c|c|c|c|c|c|c|}
\hline $\begin{array}{l}\text { LOA Tahun (LOA Years) } \\
\text { (Nomor plot) (Plot number) }\end{array}$ & $\begin{array}{c}\text { K (Batang/ha) } \\
(\text { Stems } / \text { ha })\end{array}$ & $\begin{array}{c}\mathrm{BD} \\
\left(\mathrm{m}^{2} / \mathrm{ha}\right)\end{array}$ & $\mathrm{J}$ & $\mathrm{H}^{\prime}$ & N1 & $\mathrm{E}$ \\
\hline 1. LOA4 (1) & 564 & 27,77 & 47 & 1,22 & 3,4 & 0,32 \\
\hline 2. LOA4 (2) & 671 & 24,68 & 54 & 1,30 & 3,7 & 0,33 \\
\hline 3. LOA8 & 487 & 32,70 & 32 & 1,25 & 3,5 & 0,36 \\
\hline 4. LOA10 (1) & 468 & 23,14 & 31 & 1,12 & 3,1 & 0,33 \\
\hline 5. LOA10 (2) & 566 & 30,76 & 32 & 1,16 & 3,2 & 0,33 \\
\hline 6. LOA13 & 416 & 31,72 & 29 & 1,13 & 3,1 & 0,34 \\
\hline 7. LOA14 & 540 & 28,47 & 33 & 1,32 & 3,8 & 0,38 \\
\hline 8. LOA15 (1) & 473 & 30,18 & 30 & 1,12 & 3,1 & 0,33 \\
\hline 9. LOA15 (2) & 453 & 26,80 & 26 & 1,05 & 2,9 & 0,32 \\
\hline 10. LOA33 (1) & 284 & 18,11 & 31 & 1,17 & 3,2 & 0,34 \\
\hline 11. LOA33 (2) & 485 & 25,82 & 26 & 1,13 & 3,1 & 0,35 \\
\hline Minimum & 284 & 18,11 & 26 & 1,05 & 2,85 & 0,32 \\
\hline Maksimum (Maximum) & 671 & 32,7 & 54 & 1,32 & 3,76 & 0,38 \\
\hline Rata-rata (Average) & 491,55 & 27,29 & 33,73 & 1,18 & 3,27 & 0,34 \\
\hline Kesalahan baku (Standard error) & 98,27 & 4,26 & 8,74 & 0,08 & 0,28 & 0,018 \\
\hline \multicolumn{7}{|c|}{$\begin{array}{l}\text { Sumber (Source): Susanty, (2018) dan data primer (Susanty (2018) and primer data) } \\
\text { Keterangan (Remarks): LOA = Hutan bekas tebangan (Logged over forest area) pada 4, 8, 10,13,14,15, } 33 \\
\text { tahun (years) } ; \mathrm{K}=\text { Kerapatan tegakan (Stand density); } \mathrm{BD}=\mathrm{Bidang} \text { dasar (Basal } \\
\text { area); J = Jumlah jenis (Number of species); H' = Indeks keanekaragaman } \\
\text { (Heterogeneity index) (Shannon \& Wiener); N1 = Kelimpahan jenis (Species } \\
\text { abundance); } \mathrm{E}=\text { Indeks kemerataan jenis (Species evenness index) (Pileou J) }\end{array}$} \\
\hline
\end{tabular}


Tabel (Table) 2. Analisis regresi parameter kerapatan dan keragaman tegakan pada variasi umur tebangan (Analysis regression of parameters of stand density and diversity on variation of logging aged)

\begin{tabular}{|c|c|c|c|c|c|c|c|}
\hline $\begin{array}{c}\text { Variabel terikat } \\
\text { (Dependent } \\
\text { variables) }\end{array}$ & $\begin{array}{l}\text { Persamaan regresi } \\
\quad \text { (Regression } \\
\text { equation) }\end{array}$ & $\mathrm{r}$ & $\mathrm{R}^{2}$ & $\begin{array}{c}\text { Adjusted } \\
\mathrm{R}^{2}\end{array}$ & $\mathrm{SE}$ & $\begin{array}{l}\text { F-hitung } \\
(F-\text { calc })\end{array}$ & Sig. \\
\hline \multirow[t]{4}{*}{ K } & Linear & 0,690 & 0,475 & 0,417 & 75,024 & 8,158 & 0,019 \\
\hline & Logaritma & 0,751 & 0,564 & 0,515 & 68,405 & 11,639 & 0,008 \\
\hline & Kuadratik & 0,741 & 0,550 & 0,437 & 73,724 & 4,884 & 0,041 \\
\hline & Eksponensial & 0,703 & 0,495 & 0,438 & 0,164 & 8,806 & 0,016 \\
\hline \multirow[t]{4}{*}{$\mathrm{BD}$} & Linear & 0,502 & 0,252 & 0,169 & 3,886 & 3,027 & 0,116 \\
\hline & Logaritma & 0,319 & 0,102 & 0,002 & 4,258 & 1,019 & 0,339 \\
\hline & Kuadratik & 0,653 & 0,427 & 0,283 & 3,607 & 2,978 & 0,108 \\
\hline & Eksponensial & 0,527 & 0,278 & 0,198 & 0,152 & 3,465 & 0,096 \\
\hline \multirow[t]{4}{*}{$\mathrm{J}$} & Linear & 0,589 & 0,347 & 0,275 & 7,446 & 4,785 & 0,056 \\
\hline & Logaritma & 0,807 & 0,652 & 0,613 & 5,439 & 16,830 & 0,003 \\
\hline & Kuadratik & 0,902 & 0,814 & 0,768 & 4,212 & 17,541 & 0,001 \\
\hline & Eksponensial & 0,610 & 0,372 & 0,303 & 0,190 & 5,341 & 0,046 \\
\hline \multirow[t]{4}{*}{$\mathrm{H}^{\prime}$} & Linear & 0,357 & 0,127 & 0,031 & 0,082 & 1,315 & 0,281 \\
\hline & Logaritma & 0,474 & 0,225 & 0,138 & 0,078 & 2,607 & 0,141 \\
\hline & Kuadratik & 0,542 & 0,294 & 0,117 & 0,079 & 1,665 & 0,249 \\
\hline & Eksponensial & 0,352 & 0,124 & 0,027 & 0,069 & 1,274 & 0,288 \\
\hline \multirow[t]{4}{*}{ N1 } & Linear & 0,392 & 0,154 & 0,060 & 0,274 & 1,633 & 0,233 \\
\hline & Logaritma & 0,489 & 0,239 & 0,154 & 0,260 & 2,823 & 0,127 \\
\hline & Kuadratik & 0,522 & 0,272 & 0,091 & 0,269 & 1,498 & 0,280 \\
\hline & Eksponensial & 0,392 & 0,154 & 0,060 & 0,082 & 1,633 & 0,233 \\
\hline \multirow[t]{4}{*}{ E } & Linear & 0,247 & 0,061 & $-0,044$ & 0,019 & 0,583 & 0,465 \\
\hline & Logaritma & 0,335 & 0,112 & 0,013 & 0,018 & 1,136 & 0,314 \\
\hline & Kuadratik & 0,349 & 0,122 & $-0,097$ & 0,019 & 0,556 & 0,594 \\
\hline & Eksponensial & 0,260 & 0,068 & $-0,036$ & 0,054 & 0,655 & 0,439 \\
\hline
\end{tabular}

Sumber (Source): Data primer (Primer data)

Keterangan (Remarks) : K = Kerapatan tegakan (Stand density); BD = Bidang dasar (Basal area); J = Jumlah jenis (Number of species); H' = Indeks keanekaragaman (Heterogeneity index) (Shannon \& Wiener); N1 = Kelimpahan jenis (Species abundance); $\mathrm{E}=$ Indeks kemerataan jenis (Species evenness index) (Pileou J); $\mathrm{r}=$ Koefisien korelasi (Correlation coefficient); $\mathrm{R}^{2}=$ Koefisien determinasi (Determination coefficient); $\mathrm{SE}$ $=$ Kesalahan baku (Standard error) 
Tabel (Table) 3. Persamaan regresi terpilih untuk masing-masing parameter tegakan hutan sekunder setelah penebangan (Chosen regression equation for each stand parameters of secondary logged over forest)

\begin{tabular}{ll}
\hline \multicolumn{1}{c}{ Variabel terikat (Dependent variables) } & Persamaan regresi (Regression equation) \\
\hline 1. Kerapatan (Density) & $\mathrm{y}=-81,29 \ln (\mathrm{x})+620,89$ \\
2. Bidang dasar (Basal area) & $\mathrm{y}=-0,1971 \mathrm{x}^{2}+1,9838 \mathrm{x}+24,45$ \\
3. Jumlah jenis (Number of species) & $\mathrm{y}=0,3566 \mathrm{x}^{2}-6,2434 \mathrm{x}+54,782$ \\
4. Indeks keanekaragaman (Heterogeneity index) H' & $\mathrm{y}=0,0009 \mathrm{x}^{2}-0,0243 \mathrm{x}+1,2814$ \\
5. Indeks kelimpahan (Abundance index) N1 & $\mathrm{y}=-0,184 \ln (\mathrm{x})+3,5587$ \\
6. Indeks kemerataan (Evenness index) E & $\mathrm{y}=0,0083 \ln (\mathrm{x})+0,3254$ \\
\hline
\end{tabular}

Sumber (Source): Data primer (Primer data)

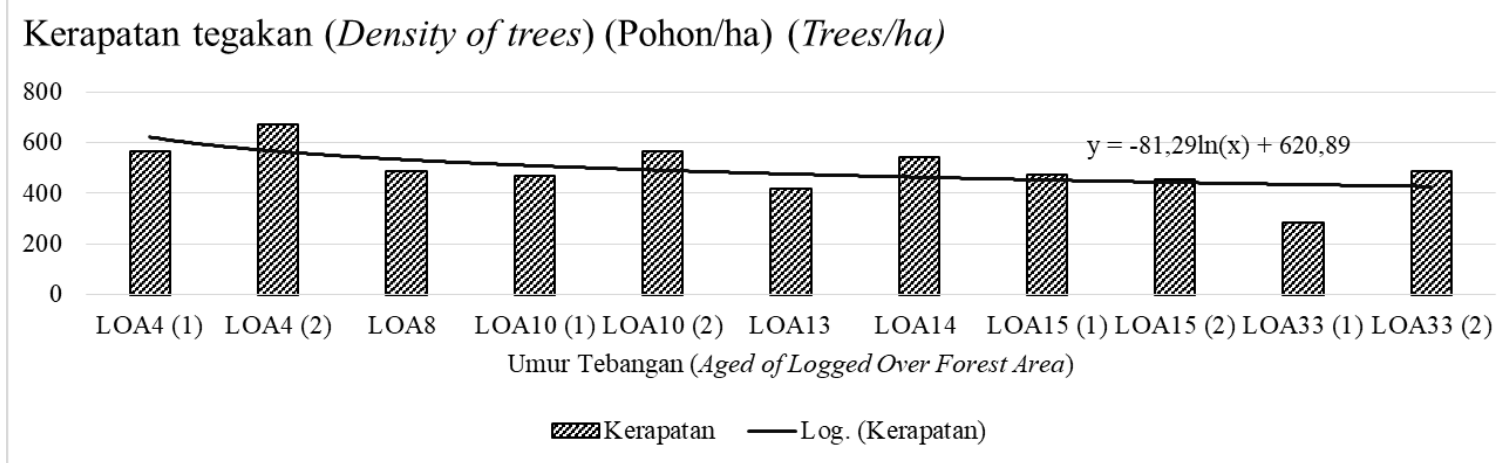

Indeks kelimpahan jenis (Species abundance index) $\left(\mathrm{N}_{1}\right)$

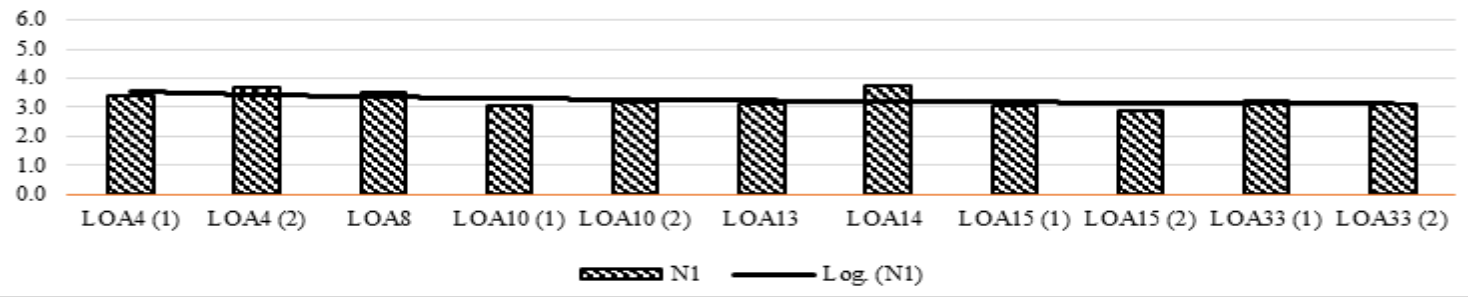

Indeks kemerataan jenis (Species evenness index) ('E)

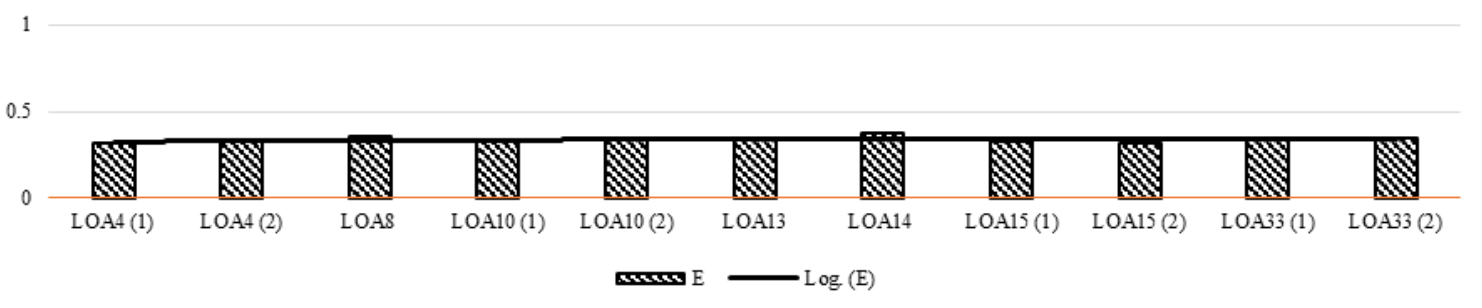

Gambar (Figure) 1. Bentuk hubungan parameter kerapatan tegakan, kelimpahan dan indeks kemerataan jenis berdasarkan umur tebangan tegakan hutan mengikuti persamaan regresi logaritma (Relationship form of parameters of stand density, abundance and evenness index based on the age of looged over forest stands follows the logarithmic regression equation) 
Pola kecenderungan hubungan masing-masing parameter tegakan terhadap umur tebangan hutan sekunder dipterokarpa ditunjukkan berdasarkan grafik garis regresi yang terpilih. Parameter kerapatan tegakan, indeks kelimpahan dan indeks kemerataan jenis mempunyai pola hubungan persamaan regresi dengan bentuk logaritma (Gambar 1). Untuk parameter bidang dasar tegakan, jumlah dan indeks keanekaragaman jenis mempunyai pola hubungan persamaan regresi dengan bentuk polynomial atau kuadratik (Gambar 2). Korelasi parameter kerapatan dan keragaman tegakan dalam hutan dipterokarpa sekunder mempunyai hubungan yang tidak linear terhadap umur tebangan. Korelasi yang paling dominan adalah jumlah jenis dengan nilai sebesar $81,4 \%$ dipengaruhi oleh faktor umur tebangan.

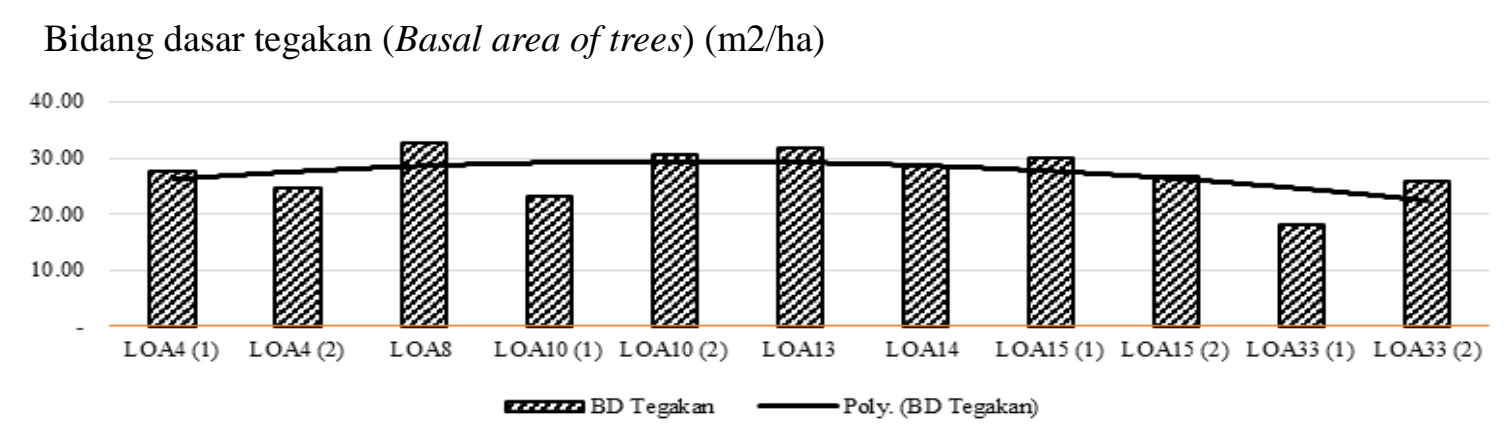

Jumlah jenis (Number of species)

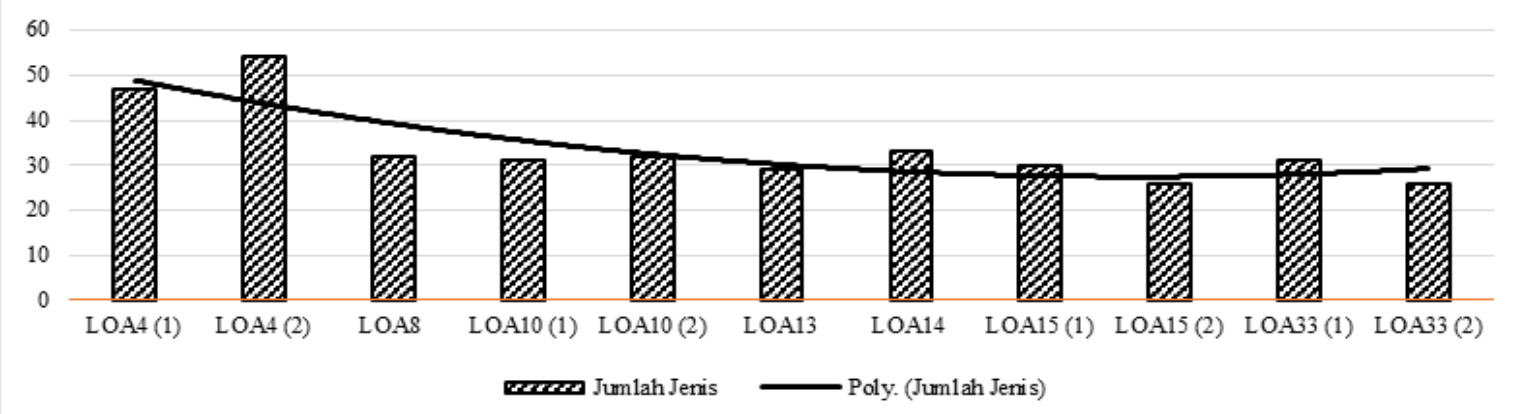

Indeks keanekaragaman (Heterogeneity index) (Shannon \& Wiener) H'

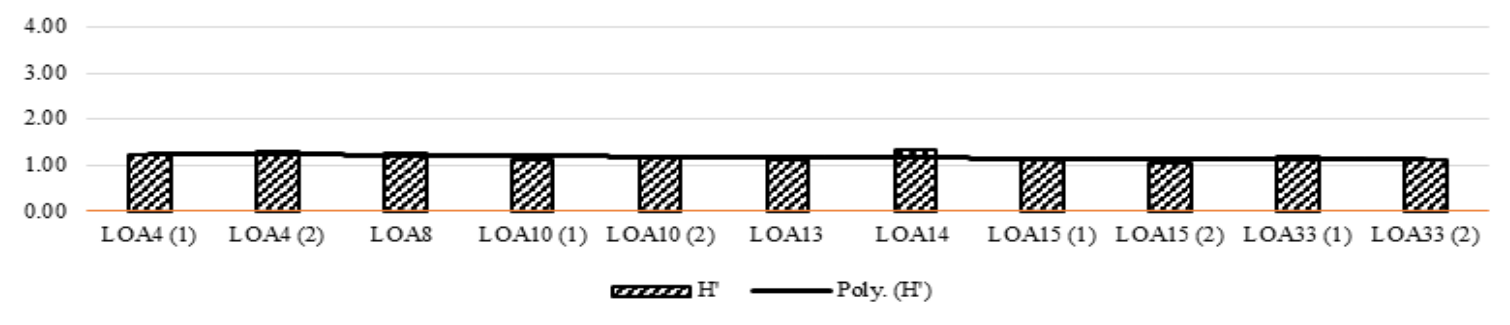

Gambar (Figure) 2. Bentuk hubungan parameter bidang dasar tegakan, jumlah dan indeks keanekaragaman jenis berdasarkan umur tebangan tegakan hutan mengikuti persamaan regresi polynomial/kuadratik (Relationship form of parameters of basal area, number of species and heterogeneity index based on the age of looged over forest stands follows the polynomial/quadratic regression equation) 


\section{B. Pembahasan}

Tegakan hutan sekunder setelah penebangan akan bervariasi dalam hal tingkat kerapatan tegakan dan keragaman komposisi jenis penyusun tegakan yang berdinamika sepanjang umur pemulihan. Pemahaman karakteristik pertumbuhan tegakan merupakan dasar dalam penentuan teknik silvikultur yang tepat dalam rangka meningkatkan atau mempercepat produktivitas hutan (Sreelekshmi et al., 2018). Variasi yang cukup lebar dari kondisi hutan karena adanya faktor genetis kecepatan pertumbuhan tegakan dan faktor biofisik lingkungan pendukungnya. Pengetahuan tentang komposisi spesies dan struktur hutan merupakan hal mendasar dalam menilai produktivitas hutan secara keberlanjutan dan status pemulihan itu sendiri (Sreelekshmi et al., 2018; Sapkota et al., 2019).

Manipulasi tegakan yang paling umum dilakukan adalah mengatur kerapatan tegakan. Hal ini dilakukan dalam rangka mengurangi kepadatan tegakan untuk memperoleh potensi hasil tegakan yang lebih berkualitas (Woods \& Watts, 2019) dan meningkatkan riap tegakan tinggal (Pretzsch, 2020). Teknik silvikultur yang dilakukan adalah penjarangan tegakan yang optimal sebagai upaya peningkatan produktivitas. Perlakuan silvikultur akan bertujuan memengaruhi struktur tegakan, sehingga produktivitas tegakan akan dapat diatur (Newton, 2019). Pengaturan kerapatan atau struktur tegakan sangat erat hubungannya dalam pengelolaan produksi hutan yang lestari.

Pada kondisi hutan alam dengan komposisi jenis yang beragam, pengaturan kerapatan tegakan akan memengaruhi keanekaragaman jenis bahkan pada pembangunan hutan tanaman sekalipun (Ali et al., 2019), yaitu pada kasus pembangunan hutan tanaman Pinus massoniana di Pegunungan Taizishan, Hubei, Cina. Hal ini disebabkan keanekaragaman sebagai pendorong adanya dinamika tegakan.
Mempertahankan keanekaragaman jenis pada tegakan hutan menjadi penting terutama telah terbukti untuk meningkatkan ketahanan tegakan terhadap gangguan alami (Jactel et al., 2017).

Portier et al., (2018) menjelaskan adanya kondisi tegakan hutan terdegradasi yang bervariasi tergantung jenis atau faktor penyebabnya baik penebangan ataupun kebakaran. Degradasi hutan akan menggeser pola kurva struktur dan komposisi tegakan. Upaya pengelolaan hutan adalah minimal mengembalikan kurva struktur tegakan dan komposisi jenis mendekati kondisi awal atau sebelum penebangan. Opsi pengelolaan yang kurang tepat akan menyebabkan hutan akan lebih rentan terhadap penyakit (Mildrexler, Shaw, \& Cohen, 2019), sehingga sangat penting untuk menentukan bentuk pengelolaan yang tepat sesuai kebutuhan dan tujuan pengelolaan itu sendiri. Pengelolaan hutan secara signifikan akan memengaruhi kondisi struktur tegakan dan faktor kondisi topografi yang spesifik akan memengaruhi karakteristik pertumbuhan secara dinamis (Baran, Pielech, Kauzal, Kukla, \& Bodziarczyk, 2020).

Penilaian pemulihan hutan tropis pada tahap awal setelah gangguan akan merubah komposisi jenis yang sangat berbeda dibandingkan dengan hutan primer (Teegalapalli \& Datta, 2016; Widiyatno et al., 2017; Susanty, 2019). Pemulihan ini berjalan berdasarkan fungsi waktu, semakin tua umur tebangan, maka kondisi tegakan semakin baik (Susanty, 2019).

Berbeda dengan aspek produktivitas tegakan, aspek biodiversitas tegakan rentan terhadap gangguan. Jenis-jenis yang mampu bertahan sangat bervariasi tergantung pada karakteristik dan sifat genetis jenis tersebut (Sann, Kanzaki, Aung, \& Htay, 2016). Hal ini menyebabkan analisis struktur tegakan menjadi lebih penting untuk mendeteksi pengelolaan daripada komposisi jenis penyusun (Baran et al., 2020). Dalam 
pengelolaan hutan dipterokarpa sekunder yang berfungsi sebagai hutan produksi, aspek produktivitas menjadi lebih dominan.

\section{KESIMPULAN DAN SARAN}

\section{A. Kesimpulan}

Kerapatan dan keragaman tegakan hutan sekunder dipterokarpa akan bervariasi sepanjang umur tebangan. Setelah penebangan, aspek produktivitas pada hutan dipterokarpa akan pulih (recovery) berdasarkan fungsi waktu, sedangkan perubahan komposisi floristik atau biodiversitas keanekaragaman hayati akan cenderung pulih dengan lebih lambat sejak adanya gangguan pada tegakan hutan. Pola kecenderungan bentuk hubungan parameter kerapatan tegakan, indeks kelimpahan dan indeks kemerataan jenis adalah bentuk logaritma, sedangkan untuk parameter bidang dasar tegakan, jumlah dan indeks keanekaragaman jenis berbentuk polynomial atau kuadratik. Pada hutan setelah penebangan, umur tegakan merupakan faktor yang memengaruhi cukup besar terhadap pemulihan parameter komposisi jumlah jenis, tetapi tidak cukup besar berpengaruh terhadap parameter kerapatan tegakan. Variasi karakteristik tegakan hutan sangat memengaruhi kondisi pemulihan tegakan hutan sekunder dipterokarpa setelah penebangan.

\section{B. Saran}

Pemulihan tegakan hutan sekunder sangat dipengaruhi oleh variasi kondisi, karakteristik tegakan dan intensitas gangguan. Faktor-faktor ini sangat menentukan terbentuknya tegakan yang dihasilkan sepanjang pertumbuhan hutan. Hal ini menjadi penting untuk melakukan kajian dengan melihat kondisi tegakan sebelum penebangan dan intensitas penebangan yang dilakukan karena keterbatasan data dalam penelitian ini.

\section{UCAPAN TERIMA KASIH}

Terima kasih disampaikan kepada Balai Besar Litbang Ekosistem Hutan Dipterokarpa yang telah memberikan dukungan untuk melakukan penelitian ini pada periode tahun 2016-2019.

\section{DAFTAR PUSTAKA}

Ali, A., Dai, D., Akhtar, K., Teng, M., Yan, Z., Urbina-Cardona, N., Mullerova, J., \& Zhou, Z. (2019). Response of understory vegetation, tree regeneration, and soil quality to manipulated stand density in a Pinus massoniana plantation. Global Ecology and Conservation, 20(1), e00775. https://doi.org/10.1016/ j.gecco.2019.e00775.

Baran, J., Pielech, R., Kauzal, P., Kukla, W., \& Bodziarczyk, J. (2020). Influence of forest management on stand structure in ravine forests. Forest Ecology and Management, 463(February), 18018.https://doi.org/ 10.1016/j.foreco.2020.118018.

Direktorat IPSDH [Inventarisasi dan Pemantauan Sumber Daya Hutan]. (2019). Rekalkulasi Penutupan Lahan Indonesia Tahun 2018. In Direktorat Inventarisasi dan Pemantauan Sumber Daya Hutan Direktorat Jenderal Planologi Kehutanan dan Tata Lingkungan. Kementerian Lingkungan Hidup dan Kehutanan.

Jactel, H., Bauhus, J., Boberg, J., Bonal, D., Castagneyrol, B., Gardiner, B., Gonzalez-Olabarria, J.R., Koricheva, J., Meurisse, N., \& Brockerhoff, E.G. (2017). Tree Diversity Drives Forest Stand Resistance to Natural Disturbances. Current Forestry Reports, 3(3), 223-243. https:// doi.org/10.1007/s40725-017-0064-1.

Mildrexler, D.J., Shaw, D.C., \& Cohen, W. B. (2019). Short-term climate trends and the Swiss needle cast epidemic in Oregon's public and private coastal forestlands. Forest Ecology and 
Management, 432(July), 501-513. https://doi.org/10.1016/j.foreco.2018. 09.025 .

Newton, P.F. (2019). Wood quality attribute models and their utility when integrated into density management decision-support systems for boreal conifers. Forest Ecology and Management, 438(November), 267284. https://doi.org/10.1016/j.foreco. 2019.01.053.

Portier, J., Gauthier, S., Cyr, G., \& Bergeron, Y. (2018). Does time since fire drive live aboveground biomass and stand structure in low fire activity boreal forests? Impacts on their management. Journal of Environmental Management, 225(August), 346-355. https://doi.org/ 10.1016/j.jenvman.2018.07.100.

Pretzsch, H. (2020). Density and growth of forest stands revisited. Effect of the temporal scale of observation, site quality, and thinning. Forest Ecology and Management, 460(January), $117879 . \quad$ https://doi.org/10.1016/ j.foreco.2020.117879.

Sann, B., Kanzaki, M., Aung, M., \& Htay, K.M. (2016). Assessment of the recovery of a secondary Tropical Dry Forest after human disturbance in Central Myanmar. Journal of Tropical Forest Science, 28(4), 479-489.

Sapkota, R.P., Stahl, P.D., \& Norton, U. (2019). Anthropogenic disturbances shift diameter distribution of woody plant species in Shorea robusta Gaertn. (Sal) mixed forests of Nepal. Journal of Asia-Pacific Biodiversity, 12(1), 115-128. https://doi.org/ 10.1016/j.japb.2018.08.004.

Sifriyani, S., Ruslan, R., \& Susanty, F.H. (2019). Mapping and Analysis Factors of Affecting Productivity Tropical Rain Forests in East Kalimantan. Modern Applied Science, 13(10), 112. https://doi.org/10.5539/mas.v13n10p1 12.

Sreelekshmi, S., Preethy, C.M., Varghese, R., Joseph, P., Asha, C.V., Bijoy Nandan, S., \& Radhakrishnan, C.K. (2018). Diversity, stand structure, and zonation pattern of mangroves in southwest coast of India. Journal of Asia-Pacific Biodiversity, 11(4), 573582. https://doi.org/10.1016/j.japb. 2018.08.001.

Susanty, F.H. (2016). Biodiversity important factors assessment on lowland Tropical Forest by ecological quantitative parameters. Jurnal Silvikultur Tropika, 7(3), S29-S30.

Susanty, F.H. (2019). Uji formulasi keragaan karakteristik biometrik pada hutan alam bekas penebangan di Kalimantan Timur. Prosiding Seminar Nasional Silvikultur Ke-6 "Penerapan silvikultur untuk pengelolaan hutan dan pengentasan kemiskinan" tegakan, 169-182.

Teegalapalli, K., \& Datta, A. (2016). Field to a forest: Patterns of forest recovery following shifting cultivation in the Eastern Himalaya. Forest Ecology and Management, 364, 173-182. https://doi.org/10.1016/j.foreco.2016.0 1.006.

Widiyatno, W., Mada, U.G., Budiadi, B., Mada, U.G., Suryanto, P., Mada, U.G., \& Hosaka, T. (2017). Recovery of vegetation structure, soil nutrient and late-succession species after shifting cultivation in Central Kalimantan, Indonesia. Journal of Tropical Forest Science, 29(2)(May), 151-162.

Woods, A.J., \& Watts, M. (2019). The extent to which an unforeseen biotic disturbance can challenge timber expectations. Forest Ecology and Management, 453(August), 117558. https://doi.org/10.1016/j.foreco.2019.1 17558 . 